ARTIGOS

\title{
Sentidos atribuídos pelos professores de séries iniciais aos desafios na carreira docente $^{12}$
}

\section{Meanings attributed by early grade teachers to the challenges in the teaching career}

(i) Universidade Federal de Santa Catarina - UFSC, Florianópolis, SC, Brasil. http://orcid.org/00000002-4846-319X, lucianeguisso@yahoo.com.br.

(ii) Universidade Federal de Santa Catarina - UFSC, Florianópolis, SC, Brasil. http://orcid.org/00000002-4091-9754,marivete@ufsc.br.

\begin{abstract}
Resumo:
O objetivo deste estudo foi o de compreender, junto aos professores dos anos iniciais do ensino fundamental, os sentidos atribuídos aos desafios na carreira docente. Doze docentes participaram de um grupo focal realizado em uma escola pública. Seus relatos foram gravados em áudio e vídeo e analisados por meio da técnica de núcleo de significação, utilizando-se como referencial teórico a perspectiva da psicologia histórico-cultural. Os dados obtidos evidenciaram que a carreira docente é vivenciada com sentimentos de prazer e angústia. Os docentes se sentem desvalorizados no exercício da profissão, tanto pelo baixo salário recebido como pelas interações que estabelecem com os estudantes, sentidas como muito complexas e desafiadoras. Comentam que sua saúde tem sido afetada, levando-os cada vez mais a buscar auxílio de especialistas e medicação para lidar com as questões do trabalho.
\end{abstract}

Palavras-chave: carreira docente, sentimentos, saúde, desgaste, medicalização

\footnotetext{
1 Apoio: Coordenação de Aperfeiçoamento de Pessoal de Nível Superior (Capes).

${ }^{2}$ Normalização, preparação e revisão textual: Aline Maya (Tikinet) - revisao@tikinet.com.br 


\title{
pro.posições
}

http://dx.doi.org/10.1590/1980-6248-2017-0187

$e$-ISSN 1980-6248

\begin{abstract}
:
The aim of this study was to understand, along with teachers from the early years of elementary school, the meanings attributed to challenges in the teaching career. Twelve teachers participated in a focus group held in a public school. Their reports were recorded in audio and video and analyzed through core signification technique, using as theoretical reference the Historical-Cultural Psychology perspective. The data obtained showed that the teaching career is experienced with feelings of pleasure and anguish. The teachers feel unappreciated in the exercise of their profession, both for the low salary they receive and for the interactions they establish with the students, felt as very complex and challenging. They say their health has been affected, leading them to increasingly seek help from specialists and medication in order to deal with work issues.
\end{abstract}

Keywords: teaching career, feelings, health, stress, medicalization

\section{Introdução}

Compreender os desafios do exercício docente com foco na carreira implica entender que essa profissão está submetida à lógica capitalista. Esse modo de visualizar o atuar dos professores possibilita considerar o assujeitamento de homens e mulheres ao assalariamento, à fragmentação do trabalho e ao atendimento de demandas cada vez mais complexas, ligadas a um contexto de rápidas transformações econômicas, políticas e sociais (Berlatto, 2011; Diehl \& Marin, 2016; Jacomini \& Penna, 2016).

Como o homem é um sujeito histórico-social, é por meio do trabalho que este consegue transformar a natureza para produzir os bens necessários à sua existência. O trabalho, desse modo, possibilita que natureza e homem se relacionem com base na ação do homem, sendo que pelo trabalho o sujeito modifica a natureza, e se modifica por meio da sua consciência (Marx, 2006). No entanto, quando o sujeito vivencia situações em que o caráter humanizador do trabalho desfalece, é afetado por reflexões e impactos (Berlatto, 2011; Lukács, 1978).

A desvalorização da carreira docente - em consequência do caráter desumanizador do trabalho experimentado - é marcada pelo momento histórico vivido. Há a vivência da desvalorização política em relação ao exercício profissional, reflexo das políticas neoliberais e das desigualdades sociais, em que os docentes enfrentam diariamente adversidades na efetivação 


\section{pro.posıções}

$e$-ISSN 1980-6248

http://dx.doi.org/10.1590/1980-6248-2017-0187

do seu trabalho (Jacomini \& Penna, 2016). Muitos presenciam a alienação em relação ao trabalho. Ou seja, os professores percebem a relação entre o que fazem e seu contratante como estranha, em função da burocratização da rotina, perdendo a propriedade daquilo que ensinam, através de avaliações padronizadas, rígido controle do conteúdo das aulas, vigilância sobre seu comportamento e dos estudantes, além da ampliação das responsabilidades e exigências quanto ao trabalho desenvolvido (Diehl \& Marin, 2016; Mattos, Perez, Almada, \& Castro, 2013). Dessa maneira, passa a se demandar que o educador seja um técnico em educação, que apenas repassa conteúdos, envolvendo-se menos com a tarefa de ensinar.

As tensões experimentadas pelos docentes são diversas na execução das atividades diárias. Há um descompasso entre o que aprenderam em suas formações iniciais e a forma como transmitem os conhecimentos aos estudantes. Além disso, os professores também relatam experimentar e visualizar muitos conflitos e violência, ou direcionados a eles mesmos ou entre os próprios estudantes, não sabendo como mediar tais situações. Mencionam sentir-se cada vez mais sozinhos para atuar com as demandas emergentes (Jacomini \& Penna, 2016). Fatores como os citados acabam por desestabilizar o exercício profissional, impondo constantes reflexões a quem decide continuar na profissão (Mattos et al., 2013).

Salienta-se que a profissão de docente é considerada pela Organização Internacional do Trabalho (OIT) como uma das mais estressantes. Ensinar se tornou uma atividade desgastante, repercutindo na saúde física, mental e no desempenho profissional (Reis, Araújo, Carvalho, Barbalho, \& Silva, 2006). Desse modo, as pressões do trabalho, os baixos salários e as cobranças das Secretarias de Educação e do Ministério da Educação vêm gerando um "mal-estar docente" (Lapo \& Bueno, 2003; Simplício \& Andrade, 2011), cujas consequências são vivenciadas nos problemas físicos (bursites, tendinites, problemas da vOz, problemas de pressão arterial) e emocionais (estresse, depressão, angústia, desânimo, apatia, impaciência, síndrome de burnout) (Eugênio, Souzas, \& Di Lauro, 2017). Essas doenças relativas ao trabalho levam muitas vezes à desilusão para com a profissão, por não fazerem sentido em relação aos anseios prévios, ocasionando a busca dos docentes pela ajuda de especialistas da saúde (como médicos psiquiatras, psicólogos) e de medicamentos para se manterem na profissão (Mattos et al., 2013).

Entende-se, dessa forma, que a carreira docente é permeada de nuances que exigem conhecimentos que vão além dos aprendidos na formação inicial. O olhar para a carreira, para os sentimentos que emergem ao longo de seu desenvolvimento, para a desvalorização sentida 


\section{pro.posıções}

http://dx.doi.org/10.1590/1980-6248-2017-0187

$e$-ISSN 1980-6248

no trabalho realizado e para os impactos na saúde são pontos fundamentais para pensar o trabalho docente frente às transformações que ocorreram na sociedade e no mundo do trabalho (Hypolito \& Grishcke, 2013). Dessa maneira, este estudo tem por objetivo compreender, junto aos docentes dos anos iniciais do ensino fundamental, os sentidos atribuidos aos desafios na carreira docente.

\section{Método}

Este artigo consiste em um recorte da pesquisa intitulada "Sentidos atribuídos às dificuldades no processo de escolarização por professoras/es dos anos iniciais do ensino fundamental", no qual optou-se por abordar o núcleo de significação "carreira docente". Essa pesquisa, de cunho qualitativo, foi realizada em uma escola pública, localizada em uma capital da região Sul do Brasil, que atende estudantes desde o $1^{\circ}$ ano do ensino fundamental até o $3^{\circ}$ ano do ensino médio. Para a obtenção das informações, foram utilizados a observação participante e o grupo focal.

A opção por professores que lecionavam para grupos escolares dos anos iniciais do ensino fundamental se deu em função da própria dinâmica da instituição. Estudantes do $1^{\circ}$ ao $5^{\circ}$ ano têm um professor principal que leciona as matérias gerais, um professor de artes e um de educação física. São professores que passam mais tempo com os estudantes, conhecendo-os mais e os acompanhando de forma mais intensa no seu processo de escolarização.

A pesquisadora foi à instituição de duas a três vezes por semana, em períodos alternados, combinados com a direção e com os próprios professores, por três meses (de março a maio de 2016), realizando observação participante, cujos dados eram anotados em diário de campo. A permanência na escola possibilitou estabelecer um canal mais próximo de comunicação e criar um vínculo com os docentes, que puderam falar mais abertamente de angústias e desafios enfrentados em sua carreira. Em função da dinâmica da instituição, os professores eram ouvidos separadamente ou em pequenos grupos, que se formavam nos horários de início de aula e intervalo. Foi ouvido um total de 22 professores ao longo do processo de observação participante, os quais, na sequência, foram convidados a participar da próxima etapa da pesquisa, que consistiu no grupo focal.

O grupo focal foi realizado no mês de maio de 2016, em uma sala da escola, e contou com a participação de 12 dos 22 professores da instituição ouvidos na primeira etapa. Durante 


\section{pro.posıções}

$e$-ISSN 1980-6248

http://dx.doi.org/10.1590/1980-6248-2017-0187

a realização do grupo focal, foram possíveis reflexões e trocas que dificilmente aconteceriam fora daquele contexto, corroborando o que já fora apontado por Kind (2004) e Carlini-Cotrim (1996) quanto à importância dessa técnica. A heterogeneidade de participantes - pois estes lecionavam nos anos iniciais do ensino fundamental - favoreceu o debate, possibilitando aprofundar a discussão do tema proposto e a participação dos professores presentes.

Foram utilizados uma câmera de vídeo e dois gravadores, dispostos em locais apropriados, na sala, para assegurar a gravação das falas do grupo. Na reunião do grupo focal, contou-se com a presença de um observador externo, que realizou anotações em relação à dinâmica do grupo e estava familiarizado com o tema de pesquisa, conforme propõe Kind (2004). O registro foi feito com a concordância dos participantes, assegurando-lhes a confidencialidade das informações e sigilo.

O projeto de pesquisa foi submetido ao Comitê de Ética em Pesquisa com Seres Humanos da Universidade Federal de Santa Catarina (CEPSH/UFSC) e aprovado sob o certificado n ${ }^{\circ}$ 51599315.6.0000.0121, em 18 de fevereiro de 2016. Foram considerados todos os procedimentos éticos relacionados aos princípios de proteção dos direitos humanos, do bemestar e da dignidade dos participantes.

A análise deste trabalho foi realizada com base nos núcleos de significação, conforme descritos por Aguiar e Ozella (2006, 2013). Essa técnica permite que se apreendam os sentidos do material qualitativo por meio da análise e organização de etapas, a saber: pré-indicadores, sistematização dos indicadores, e sistematização dos núcleos de significação. Neste trabalho, analisaram-se os resultados do núcleo "carreira docente", que foi agrupado nos seguintes indicadores: (i) sentimento em relação à escolha da carreira docente; (ii) desvalorização da profissão; e (iii) saúde docente.

\section{Resultados e discussão}

Perante as mudanças relativas à universalização do ensino, a carreira docente tem passado por constantes mudanças e considerações. Tal contexto exige do docente habilidades e reflexões diversas. Além disso, os professores têm precisado enfrentar situações cada vez mais extenuantes em relação ao exercício da profissão, e a carreira docente tem passado por 


\section{pro.posıções}

http://dx.doi.org/10.1590/1980-6248-2017-0187

$e$-ISSN 1980-6248

mudanças que influenciam na própria efetividade e qualidade do trabalho oferecido (Nunes \& Oliveira, 2017).

Em relação ao núcleo de significação "carreira docente", os professores revelaram que, apesar de não se sentirem respeitados pelos estudantes, da sobrecarga de trabalho e da desvalorização social da profissão, a escolheriam novamente, pois “amam ensinar". Mesmo com a insatisfação vivenciada ao longo dos anos de profissão, os profissionais do grupo focal se identificavam com seu trabalho, dizendo sentir prazer em fazê-lo. Porém, o processo de ensinar tem desencadeado realidades de desvalorização do trabalho, assim como reflexos em sua saúde que são sentidos todos os dias.

Com o intuito de melhor entender os sentidos produzidos pelos professores em relação à carreira docente, organizou-se a interpretação das narrativas dos docentes do grupo focal em torno de indicadores, detalhados na sequência deste trabalho.

\section{Sentimento em relação à escolha da carreira docente}

Esse indicador aponta como os professores ouvidos se sentiam ao longo do exercício da docência e se escolheriam a mesma profissão caso precisassem realizar uma nova escolha de carreira em suas vidas. Para uma das professoras ouvidas no grupo focal, o sentimento que transparece em relação a ser professora remete ao amor. Ela relata: “Amo ser professora. Uma coisa que ninguém tira isso de mim. Já estou bá 22 anos professora, vou fazer este ano" (Fernanda, 2016)3.

Em pesquisa realizada no Reino Unido por Hargreaves et al. (2006), os autores estudaram as razões de escolha da profissão por professores em exercício e por estagiários do curso de Pedagogia. Pôde-se constatar que, em ambos os grupos, as falas voltavam-se para realização profissional, busca por um trabalho com estatuto confortável, desenvolvimento pessoal, possibilidade de auxiliar as crianças em seu desenvolvimento, e visualização do fato de ser um trabalho desafiante. Assim, tanto no citado estudo como na fala da professora Fernanda, a escolha de carreira reflete um sentimento de pertença à profissão e de realização quanto à

\footnotetext{
3 Todos os nomes dos professores citados neste trabalho são fictícios, respeitando o sigilo preconizado no Termo de Consentimento Livre e Esclarecido (TCLE) assinado por eles na realização do grupo focal.
} 


\section{pro.posıções}

http://dx.doi.org/10.1590/1980-6248-2017-0187

$e$-ISSN 1980-6248

escolha profissional, o que envolve a dimensão afetiva experimentada na relação com os estudantes (Neves \& Silva, 2006).

Os professores ouvidos também relataram que a escolha profissional foi acertada. Ou seja, caso necessitassem escolhê-la novamente, o fariam. Isso é mencionado na fala de uma docente, quando diz: "Agora eu vou dizer uma coisa. Eu seria professora, seria professora outras vezes, se en tivesse que escolher" (Ana, 2016). Salienta-se que as razões para se tornar professor podem variar, sendo essa escolha multidimensional, mesmo que às vezes seja vista como "quase profissão" quando comparada a carreiras tradicionais (advogados, médicos, arquitetos) (Alves, Azevedo, \& Gonçalves, 2014).

As falas das professoras citadas vão ao encontro das informações apontadas por Neves e Silva (2006). Para esses autores, o sentido ou a significação do trabalho apresenta-se como ponto fundamental na relação com o desejo e o prazer, uma vez que não configura questão de mera satisfação, mas de realização profissional. $\mathrm{Na}$ fala de outra professora, esta ratifica sua escolha profissional: "Eu escolheria ser professora. Mesmo com tudo isso assim. Por isso que às vezes eu me angustio" (Ana, 2016).

É importante destacar que, no trecho apresentado, o sentimento em relação à escolha profissional vem permeado de angústia. Muitos professores vivenciam essa contradição em relação à carreira no dia a dia. Dejours (1992) salienta que prazer e angústia se misturam na atividade docente.

A angústia experimentada pelos docentes está relacionada ao sentimento de poderem executar sua atividade de forma ineficaz, de serem responsabilizados pelo fracasso escolar dos estudantes, de não terem o controle da turma, entre outros motivos. Também há pressões para que o educador mude sua forma de atuar e busque novas práticas educativas para trabalhar diante do "novo" que se apresenta no cotidiano escolar, precisando de novos conhecimentos para lidar com os conflitos vivenciados (Leite, 2014). Entende-se, dessa maneira, que o trabalho docente é fonte de satisfação e realização bem como de estresse e desgaste (Johnson et al., 2005). Desse modo, compreender a atuação docente e sua inserção na sociedade possibilita perceber como os sentimentos envolvidos na atuação diária são complexos e, muitas vezes, ambíguos (Eugênio, Souzas, \& Di Lauro, 2017).

Assim, o sentido dado pelos professores ao indicador "sentimento em relação à escolha da carreira docente" é perpassado tanto pela satisfação (relacionada ao ato de ensinar) quanto 


\section{pro.posıções}

http://dx.doi.org/10.1590/1980-6248-2017-0187

$e$-ISSN 1980-6248

pela angústia (relacionada aos diversos desafios presenciados por eles na prática educativa). Os docentes afirmam valorizar seu trabalho, mas sofrem quando não conseguem realizá-lo da forma como gostariam. Há, dessa maneira, uma ambiguidade nos sentimentos expressos, que muitas vezes são pouco compartilhados e entendidos no contexto escolar, refletindo em maior solidão experimentada pelos docentes diariamente em seu trabalho.

\section{Desvalorização da profissão}

O tema da desvalorização da profissão de professor no Brasil vem sendo recorrente em debates sindicais, acadêmicos e governamentais. Considera-se que a valorização dessa carreira está associada à garantia de condições de trabalho, renumeração, formação inicial e continuada (Grochoska, 2015; Masson, 2017). Dessa forma, a efetivação dos elementos citados vincula-se à própria emancipação política da categoria.

No indicador "desvalorização da profissão", os professores comparam as lembranças do início de sua atuação profissional com a percepção atual, no que se refere à valorização social do seu fazer. Destacam que perceberam a desvalorização da carreira com o passar do tempo, principalmente relacionada à diminuição do salário recebido. Segundo uma das professoras: "Antigamente tu ser professora, escolher esse ofício, era um atestado do teu bom caráter. Tu éprofessora porque tu tem um exemplo pra dar para men filho, por exemplo. Hoje pelo baixo salário, pelo que falam na mídia, mudou" (Indianara, 2016). Conforme essa fala, as condições precárias de trabalho e a baixa renumeração influenciam no reconhecimento negativo do exercício da profissão docente, corroborando o estudo realizado por Noronha, Assunção e Oliveira (2008).

Entende-se que a escolha profissional e a inserção no mercado de trabalho perpassam a escolha subjetiva, uma vez que abrangem condições econômicas e socioculturais dos jovens candidatos a docentes (Masson, 2017). Consequentemente, a baixa renumeração é um dos grandes componentes que influenciam a inserção e permanência na carreira. Esse aspecto é refletido na conversa do grupo focal: "E onde começou a desvalorização do professor?" (Joana, 2016); "Primeiro, socialmente, pelo salário. Foi diminuindo, diminuindo... Porque socialmente toda a profissão tem um valor social' (Indianara, 2016). Gatti e Barreto (2009) comentam que o salário docente não é atraente se comparado com outras profissões que exigem ensino superior, e verifica-se também a ausência de planos estruturados para pensar a carreira de forma mais sólida. Assim, as autoras 


\section{pro.posıções}

$e$-ISSN 1980-6248

http://dx.doi.org/10.1590/1980-6248-2017-0187

abordam que tanto a renumeração como o preparo para a docência não correspondem às responsabilidades sociais implicadas no exercício da função. Esse contexto é ilustrado na fala da professora Indianara, que se refere à perda do valor social da profissão ao longo dos anos.

Ratifica-se, ainda, que os baixos salários pagos aos professores - como no ensino fundamental público (objeto deste estudo) - limitam seu acesso a serviços de saúde especializados, práticas de lazer e transporte de qualidade, influenciando de maneira gradativa nos sentimentos de desvalorização por eles experienciados (Fernandes \& Rocha, 2009). Destaca-se também que, muitas vezes, o próprio espaço em que os profissionais se encontram contribui para essa desvalorização quando pouco se investe em capacitações, formação continuada, grupos de discussão e paradas pedagógicas (Pereira, Teixeira, \& Lopes, 2013).

Souza et al. (2003) indicam que, até os anos 1960, a maioria dos docentes gozava de relativa segurança material, emprego estável e prestígio social na realização do seu trabalho. Com as transformações sociais ocorridas a partir dos anos 1970, os docentes sofreram o impacto decorrente das novas políticas em vigor na sua profissão, trazendo consequências para a afirmação da identidade profissional. $\mathrm{O}$ trabalho pedagógico foi parcelado, transformando-se em uma verdadeira linha de montagem em que os técnicos (orientadores pedagógicos, coordenadores), que supostamente sabem mais, têm poder e maiores salários do que os professores (Patto, 1992).

Os docentes dizem sentir a desvalorização da sua profissão também pela forma como os estudantes os tratam. Mencionam que sentem diferença do respeito que os estudantes manifestam para com eles atualmente em comparação com o início do exercício da profissão. $\mathrm{Na}$ fala de uma das professoras, isso fica evidente:

Eu estou há 30 anos no magistério, desde 1986, tá? Eu dei aula 18 anos no bairro onde eu morava. Assim, oh, eu me sentia respeitada pelo meu aluno. Eu era a professora.... Não era uma professora, não era que en queria me fazer, ser melhor. Mas era assim, ob! Uma questão de respeito. (Ana, 2016)

Entende-se que a profissão docente foi afetada por mudanças sociais, econômicas, políticas e tecnológicas (Nunes \& Oliveira, 2017). Ou seja, antigamente o professor era respeitado como a única fonte de saber. Porém, com a democratização do acesso às informações, a profissão docente foi afetada em seu reconhecimento social, precisando esse profissional repensar formas de reafirmar seu espaço e sua identidade (Zacharias et al., 2011). 


\section{pro.posições}

http://dx.doi.org/10.1590/1980-6248-2017-0187

$e$-ISSN 1980-6248

Neves e Silva (2006) apontam que o sujeito busca, em seu trabalho, ser reconhecido socialmente. Esse processo de contribuição-retribuição traz consequências positivas para a estruturação da identidade e da saúde mental. O reconhecimento social tem um componente simbólico importante, uma vez que auxilia na construção do sentido do trabalho. $\mathrm{Na}$ fala de uma das professoras, é possível perceber sua constatação quanto ao reconhecimento percebido em relação aos estudantes:

É que hoje tu passa e eles sabem que nós somos professoras; os alunos, parece que a gente é invisivel aos olhos deles. Quem atravessa ai o pátio no horário das entradas, parecem que nós somos invisiveis, se eles tiverem que passar eles passam por cima da gente. (Ana, 2016)

Os docentes percebem que houve mudanças em relação ao público que atendem, bem como na forma de se relacionar com os estudantes. Tal fato se reflete na exigência de novas habilidades sociais por parte dos docentes para lidar com a diversidade de situações presenciadas no contato com os estudantes (Pasqualotto \& Löhr, 2015).

Dessa forma, os sentidos atribuídos pelos docentes à "desvalorização da profissão" indicam aspectos relacionados tanto à política educacional (referente aos programas e auxílios à categoria) como ao próprio reconhecimento da profissão pelos estudantes, uma vez que os professores indicam que não se sentem mais tratados como eram antigamente. Os docentes apontam, nesse indicador, que entre os motivos que os levam a seguir na profissão, mesmo com a desvalorização presenciada diariamente, estão aspectos afetivos, como: gosto pela profissão, a crença na importância do trabalho realizado, e a realização profissional. Desse modo, é preciso considerar o momento histórico em que os profissionais se encontram e as alterações nas políticas educacionais que repercutem no seu dia a dia. Também é preciso pensar que as mudanças pelas quais a sociedade passa corroboram o fraco investimento em capacitação e na qualidade das condições de trabalho docente. Acredita-se que são necessários enfrentamentos em relação à desvalorização profissional, uma vez que esses desafios presenciados pelos professores têm refletido no exercício da profissão, bem como na sua permanência ou abandono da carreira. 


\section{pro.posições}

http://dx.doi.org/10.1590/1980-6248-2017-0187

$e$-ISSN 1980-6248

\section{Saúde docente}

Salienta-se que os estudos sobre saúde e trabalho docente no contexto brasileiro datam desde 1990 (Araújo \& Carvalho, 2009). As investigações que vêm sendo realizadas demonstram associações entre condições de trabalho e comorbidades como burnout, disfonia, transtornos mentais, problemas físicos e psicológicos. A consequência disso, muitas vezes, é o afastamento e/ou abandono pelos professores de suas carreiras devido ao sofrimento vivenciado (Baião \& Cunha, 2013; Pereira, Teixeira, \& Lopes, 2013; Santos \& Marques, 2013).

Assim, no indicador "saúde docente", os professores comentam sobre como percebem sua disponibilidade física e emocional na execução de suas funções no decorrer dos anos. Retratam que as condições de trabalho vivenciadas têm interferido em seu bem-estar, gerando desconforto e adoecimento. Desse modo, mencionam que recorrem à ajuda de especialistas da saúde (médicos e psicólogos) e à medicação para permanecerem ativos no exercício da profissão.

Ante exigências cada vez mais amplas no desenvolvimento do trabalho docente, muitos acabam não conseguindo atender às demandas que lhes são solicitadas. Essa situação pode provocar enfermidades físicas e psicológicas decorrentes do estresse vivenciado para manter o trabalho (Pasqualotto \& Löhr, 2015). Para uma das professoras ouvidas no grupo focal, há uma relação direta entre o trabalho que realiza e os efeitos sentidos em sua saúde física e mental. Ela comenta: "Se eu disser para vocês que na segunda-feira... Não, na sexta-feira, eu estava doente. Na sextafeira à tarde en vim trabalhar. Porque o remédio não me deixou eu nem dormir. Eu não consegui" (Liana, 2016).

Essa fala é recorrente entre os docentes da instituição estudada. Estes se dizem exaustos e sentem reflexos do trabalho em sua voz, em seu corpo, no sono e nos pensamentos. São inúmeros os conflitos que os professores precisam administrar diariamente, o que afeta seu bem-estar. Compreende-se, desse modo, que as circunstâncias em que os docentes mobilizam suas capacidades físicas, cognitivas e afetivas são diversas, corroborando para o esforço no exercício da profissão (Gasparini, Barreto, \& Assunção, 2005).

Dejours (1992) aborda que os trabalhadores buscam defesas individuais e coletivas para enfrentar o sofrimento. Entende-se que os sujeitos não são passivos perante a organização do trabalho, elaborando defesas e buscando formas de resolvê-las. Essas estratégias são buscadas 


\section{pro.posıções}

$e$-ISSN 1980-6248

http://dx.doi.org/10.1590/1980-6248-2017-0187

pelos professores ouvidos, uma vez que recorrem a outros profissionais para compreendê-los e auxiliá-los em sua saúde.

$\mathrm{Na}$ observação participante realizada, durante a permanência na instituição, muitos docentes relataram que são acompanhados por especialistas (psiquiatras e psicólogos) e fazem uso de auxílio medicamentoso. Sentem-se pressionados pelo calendário acadêmico, pelo ensino que precisam assegurar aos estudantes e pela administração dos conflitos diários experimentados com os alunos em sala de aula. Percebem, também, a transferência da responsabilidade institucional para eles, que precisam gerenciar sozinhos as demandas da sala de aula (Gasparini, Barreto, \& Assunção, 2005), o que os sobrecarrega, implicando no desgaste e adoecimento vivenciado.

Destaca-se que o recurso a medicamentos tem aumentando consideravelmente. Pesquisas nesse campo são raras, o que aponta uma lacuna na literatura sobre o tema. Esse é um assunto preocupante, uma vez que, para aguentar o trabalho e suas demandas, os profissionais precisam recorrer a um "controle químico" para se acalmarem e manterem, dentro do possível, a regulação que não conseguem obter no local e nas relações de trabalho que vivenciam (Eugênio, Souzas, \& Di Lauro, 2017).

Desse modo, percebe-se que a saúde do docente é uma preocupação periférica no setor da educação, tanto na visão dos gestores escolares como na dos próprios docentes. Autores como Araújo e Carvalho (2009) destacam que isso ocorre porque o professor é acostumado a cuidar do outro, mas há dificuldades em olhar para si, para o seu bem-estar, sua saúde e seus limites. Assim, a busca de auxílio é mencionada quando os docentes verificam que estão em um patamar avançado em relação aos efeitos do adoecimento sentido.

Salienta-se, desse modo, que as doenças desencadeadas no trabalho docente são significadas enquanto um processo individual, ou seja, uma dificuldade pessoal ou inadequação do docente ao trabalho (Araújo \& Carvalho, 2009). Pouco se aborda o caráter coletivo do adoecer e a configuração do trabalho. Compreende-se que essa visão mais ampla sobre o adoecer docente ainda precisa ser construída enquanto demanda coletiva associada à estrutura organizativa do trabalho em que os profissionais dessa área estão inseridos, e não enquanto algo de caráter individual, como vem sendo apresentado.

Desse modo, os sentidos atribuídos ao indicador "saúde docente" apontam que os professores se encontram sobrecarregados no exercício de sua função. Eles sentem os efeitos 


\section{pro.posıções}

$e$-ISSN 1980-6248

http://dx.doi.org/10.1590/1980-6248-2017-0187

do trabalho em seu bem-estar físico e psicológico. Ficam angustiados, ansiosos, com dores nas costas, problemas de voz, frustrados em relação às demandas que precisam atender e ao respaldo real que conseguem dar na prática. Além disso, os docentes significam os efeitos na saúde como processos individuais, uma vez que as estratégias adotadas são de âmbito pessoal, dificilmente acolhidas pela instituição de ensino e pelos programas docentes.

Por fim, aponta-se que o núcleo "carreira docente" aborda os sentidos dados pelos professores ao desenvolvimento de suas carreiras. A escolha da profissão é permeada por sentimentos de prazer em ensinar e em ver os estudantes avançando no conhecimento. Os docentes também mencionam sentimentos de angústia em relação ao trabalho que precisam realizar, ao calendário que precisam cumprir, à falta de (ou ao pouco) suporte da coordenação da instituição em que lecionam, e aos embates que vivenciam com os estudantes diariamente. Os professores dizem experimentar a desvalorização de seu salário, reflexo da precarização das condições de trabalho no decorrer dos anos. Percebem que sua relação com o trabalho afeta diretamente a sua saúde. Mencionam que, com o passar do tempo, os desafios da carreira aumentaram. Sentem pelo perfil dos estudantes que precisam ensinar e pela relação com eles, que avaliam como distanciada. Vivenciam os reflexos disso em sua saúde, uma vez que sentem os efeitos do cansaço, do sono que não vem, e das preocupações diárias. Desse modo, restam saídas individuais para os desafios enfrentados, como o auxílio de especialistas da saúde, bem como o tratamento de saúde medicamentoso. Aponta-se que, na visão do grupo de professores ouvidos, os sentidos dados a sua carreira são ancorados na percepção de solidão e isolamento, seja em relação aos demais agentes escolares, seja na relação com os estudantes. Desse modo, os docentes acabam resistindo sozinhos, buscando, cada um a seu modo, estratégias e outros modos de atuação profissional ante uma realidade cada vez mais complexa, a qual demanda grande engajamento coletivo dos docentes para a construção de estratégias educativas mais potentes para todos os atores da escola. 


\section{pro.posıções}

http://dx.doi.org/10.1590/1980-6248-2017-0187

\section{$e$-ISSN 1980-6248}

\section{Considerações finais}

O objetivo deste artigo foi compreender, com os docentes dos anos iniciais do ensino fundamental, os sentidos atribuídos aos desafios na carreira docente. Os dados obtidos neste trabalho corroboram estudos já realizados sobre os sentimentos destacados pelos docentes em relação ao exercício da profissão. A realização e a vivência da carreira docente são significadas pelos sentimentos de amor à profissão e angústia. Os docentes mencionam que se sentem bem com a escolha profissional e optariam por ela novamente, caso precisassem fazer uma nova escolha de carreira. Porém, sentem-se pressionados pelo calendário acadêmico, pela própria escola e pelas famílias para dar resultados sempre consistentes. Mencionam que se sentem sozinhos em sala de aula para realizar seu trabalho. Recebem pouco respaldo da coordenação, dos próprios programas de formação de professores e das políticas públicas para balizar suas práticas.

A desvalorização da profissão também foi debatida pelos professores. Estes dizem perceber que a profissão vem perdendo seu valor social no decorrer do tempo. Já não se sentem mais valorizados como outrora por seus estudantes e comentam que o salário recebido não é atraente. Assim, cada vez mais significam a carreira como solitária, tendo pouco investimento em formação, estrutura e condições de ensino que lhes permitam seguir ativos nessa função.

Os docentes destacaram que, em decorrência das transformações vivenciadas ao longo da profissão, sentem os efeitos das condições de trabalho em sua saúde física e emocional. $\mathrm{Na}$ percepção deles, o trabalho tem desencadeado doenças que os levam a procurar ajuda de profissionais de saúde (médicos e psicólogos), bem como tratamentos medicamentosos para permanecerem exercendo a profissão. A medicalização da profissão é um dado que precisa ser mais bem investigado, com a finalidade de se conhecer a realidade dos profissionais que estão trabalhando mesmo doentes. Considerado uma das profissões mais estressantes de todos os tempos, o trabalho docente traz reflexões que precisam ser aprofundadas, uma vez que suas dificuldades têm refletido na saúde desses profissionais, que recorrem ao controle químico para se manter trabalhando.

Acredita-se que investir em novas pesquisas e projetos de extensão com os docentes, permitindo-lhes falar de seus sentimentos no exercício da profissão, pode contribuir para a promoção de saúde. Possibilitar que os docentes reflitam sobre suas práticas e suas demandas pode resultar em momentos significativos de valorização da prática e da carreira docente. Desse 


\section{pro.posições}

http://dx.doi.org/10.1590/1980-6248-2017-0187

$e-$ ISSN 1980-6248

modo, fomentar espaços coletivos de discussão potencializa a valorização de práticas mais acolhedoras e agregadoras em relação ao bem-estar e à produção de novos sentidos para a carreira docente, a fim de buscar novas saídas para o momento de inércia presente.

Por fim, defende-se que é necessário também ampliar a discussão sobre a carreira docente, com ênfase na dimensão macropolítica, que está relacionada à forma como as políticas públicas educacionais estão organizadas e aos efeitos que isso produz no trabalho docente. Acredita-se que a expansão da discussão sobre a carreira docente para além dos muros da escola é fundamental para a promoção de processos educativos inclusivos para todos os atores sociais da escola.

\section{Referências}

Aguiar, W. M. J., \& Ozella, S. (2006). Núcleos de significação como instrumento para apreensão da constituição dos sentidos. Psicologia, Ciência e Profissão, 26(2), 222-245.

Aguiar, W. M. J., \& Ozella, S. (2013). Núcleos de significação: Aprimorando a proposta dos núcleos de significação. Revista Brasileira de Estudos Pedagógicos, 94(236), 299-322.

Alves, M. G., Azevedo, N. R., \& Gonçalves, T. N. R. (2014). Satisfação e situação profissional: Um estudo com professores nos primeiros anos de carreira. Educação e Pesquisa, 40(2), 365-382.

Araújo, T. M., \& Carvalho, F. M. (2009). Condições de trabalho docente e saúde na Bahia: Estudos epidemiológicos. Educação \& Sociedade, 30(107), 427-449.

Baião, L. P. M., \& Cunha, R. G. (2013). Doenças e/ou disfunções ocupacionais no meio docente: Uma revisão de literatura. Formação@Docente, 5(1),6-21.

Berlatto, A. C. (2011). A valorização do trabalho do professor para além da remuneração. Dissertação de mestrado, Universidade Federal de Santa Catarina, Florianópolis.

Carlini-Cotrim, B. (1996). Potencialidades da técnica qualitativa grupo focal em investigações sobre abuso de substâncias. Revista de Saúde Pública, 30(3), 285-293.

Dejours, C. (1992). Travail: Usure mentale. Paris: Bayard Éditions. 


\section{pro.posıções}

http://dx.doi.org/10.1590/1980-6248-2017-0187

$e$-ISSN 1980-6248

Diehl, L., \& Marin, A. H. (2016). Adoecimento mental em professores brasileiros: Revisão sistemática da literatura. Estudos Interdisciplinares em Psicologia, 7(2), 64-85.

Eugênio, B., Souzas, R., \& Di Lauro, A. D. (2017). Trabalho e adoecimento do professor da educação básica no interior da Bahia. Laplage em Revista, 3(2), 179-194.

Fernandes, M. H., \& Rocha, V. M. (2009). Impact of the psychosocial aspects of work on the quality of life of teachers. Revista Brasileira de Psiquiatria, 31(1), 15-20.

Gasparini, S. M., Barreto, S. M., \& Assunção, A. A. (2005). O professor, as condições de trabalho e os efeitos sobre sua saúde. Educação e Pesquisa, 31(2), 189-199.

Gatti, B. A., \& Barreto, E. S. (2009). Professores do Brasil: Impasses e desafios. Brasília, DF: Unesco.

Grochoska, M. A. (2015). Políticas educacionais e a valorização do professor: Carreira e qualidade de vida dos professores de educação básica do município de São José dos Pinhais/PR. Tese de Doutorado, Universidade Federal do Paraná, Curitiba.

Hargreaves, L., Cunningham, M., Everton, T., Hansen, A., Hopper, B., McIntyre, D., Oliver, C., Pell, T., Rouse, M., \& Turner, P. (2006). The status of teachers and the teaching profession: Views from inside and outside the profession: Interim findings from the teacher status project (Research Report). London: DfES.

Hypolito, A. M., \& Grishcke, P. E. (2013). Trabalho imaterial e trabalho docente. Educação: Revista do Centro de Educação da Universidade Federal de Santa Maria, 38(2), 507-522.

Jacomini, M. A., \& Penna, M. G. O. (2016). Carreira docente e valorização do magistério: Condições de trabalho e desenvolvimento profissional. Revista Pro-Posições, 27(2), 177 202.

Johnson, S. M., Cooper, C., Cartwright, S., Donald, I., Taylor, P. J., \& Millet, C. (2005). The experience of work-related stress across occupations. Journal of Managerial Psychology, $20(2), 178-187$.

Kind, L. (2004). Notas para o trabalho com a técnica de grupos focais. Psicologia em Revista, 10(15), 124-136.

Lapo, F. B., \& Bueno, O. B. (2003). Professores, desencanto com a profissão e abandono do magistério. Cadernos de Pesquisa, 118, 65-88. 


\section{pro.posıções}

http://dx.doi.org/10.1590/1980-6248-2017-0187

\section{$e$-ISSN 1980-6248}

Leite, M. A. (2014). Encontros e (re)encontros com imagens docentes: Uma análise discursiva. Fórum linguístico, 11(4), 415-428.

Lukács, G. (1978). As bases ontológicas do pensamento e da atividade do homem. Revista Temas de Ciências Humanas, (4), 1-17.

Marx, K. (2006). O capital: Crítica da economia política (23ª ed., Livro I). Rio de Janeiro: Civilização Brasileira.

Masson, G. (2017). Requisitos essenciais para a atratividade e a permanência na carreira docente. Educação \& Sociedade, 38(140), 849-864.

Mattos, A. R., Perez, B. C., Almada, C. V. R., \& Castro, L. R. (2013). O cuidado na relação professor-aluno e a sua potencialidade política. Estudos de Psicologia, 18(2), 369-377.

Neves, M. Y. R., \& Silva, E. S. (2006). A dor e a delícia de ser (estar) professora: Trabalho docente e saúde mental. Estudos e Pesquisas em Psicologia, 6(1), 63-75.

Noronha, M. M. B., Assunção, A. A., \& Oliveira, D. A. (2008). O sofrimento no trabalho docente: O caso das professoras da rede pública de Montes Claros, Minas Gerais. Revista Trabalho Educação e Saúde, 6(1), 65-85.

Nunes, C. P., \& Oliveira, D. A. (2017). Trabalho, carreira, desenvolvimento docente e mudança na prática educativa. Educação \& Pesquisa, 43(1), 65-80.

Pasqualotto, R. A., \& Löhr, S. S. (2015). Habilidades sociais e resiliência em futuros educadores. Psicologia Argumento, 33(80), 310-320.

Patto, M. H. S. (1992). A família pobre e a educação pública: Anotações sobre um desencontro. Psicologia USP, 3(1-2), 107-121.

Pereira, F. E., Teixeira, C. S., \& Lopes, A. S. (2013). Qualidade de vida de professores de educação básica do município de Florianópolis, SC, Brasil. Ciência \& Saúde Coletiva, 18(7), 1963-1970.

Reis, E. J. F. B., Araújo, T. M., Carvalho, F. M., Barbalho, L., \& Silva, M. O. (2006). Docência e exaustão emocional. Educação e Sociedade, 27(94), 229-253.

Santos, M. N., \& Marques, A. C. (2013). Condições de saúde, estilo de vida e características de trabalho de professores de uma cidade do sul do Brasil. Ciência \& Saúde Coletiva, 18(3), 837-846. 


\section{pro.posıções}

$e$-ISSN 1980-6248

http://dx.doi.org/10.1590/1980-6248-2017-0187

Simplício, S. D., \& Andrade, M. S. (2011). Compreendendo a questão da saúde dos professores da Rede Pública Municipal de São Paulo. Psico, 42(2), 159-167.

Souza, K. R., Santos, M. B. M., Pina, J. A., Maria, A. B. V., Carmo, M. A., \& Jesen, M. (2003). A trajetória do Sindicato Estadual dos Profissionais da Educação do Rio de Janeiro (Sepe-RJ) na luta pela saúde no trabalho. Ciência \& Saúde Coletiva, 8(4), 1057-1068.

Zacharias, J., Mendes, A. R., Lettnin, C., Dohms, K. P., Mosquera, J. J. M., \& Stobäus, C. D. (2011). Saúde e educação: Do mal-estar ao bem-estar docente. Revista Educação por Escrito, 2(1), 16-30.

Submetido à avaliação em 9 de dę̧embro de 2017; aceito para publicação em 23 de junho de 2018. 